\title{
Conf-950454-1
}

UCRL-JC-118757

L-19102-1

PREPRINT

\section{Diode Laser Absorption Spectroscopy for Process Control- Sensor System Design Methodology}

\author{
L. V. Berzins \\ T. M. Anklam \\ F. Chambers \\ S. Galanti \\ C. A. Haynam \\ E. F. Worden
}

This paper was prepared for submittal to the International Conference on Metallurgical Coatings and Thin Films San Diego, California

April 24- 28, 1995

March 1995

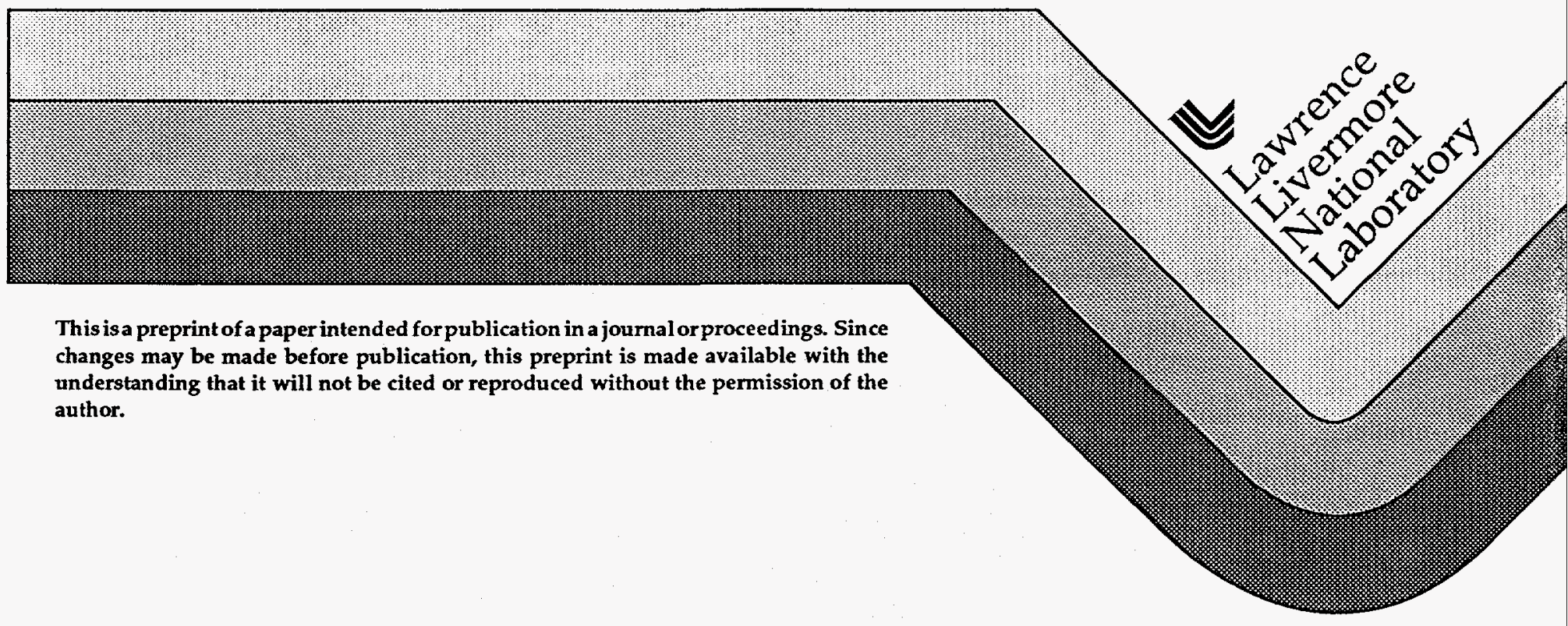




\section{DISCLAIMER}

This document was prepared as an account of work sponsored by an agency of the United States Government. Neither the United States Government nor the University of California nor any of their employees, makes any warranty, express or implied, or assumes any legal liability or responsibility for the accuracy, completeness, or usefulness of any information, apparatus, product, or process disclosed, or represents that its use would not infringe privately owned rights. Reference herein to any specific cornmercial products, process, or service by trade name, trademark, manufacturer, or otherwise, does not necessarily constitute or imply its endorsement, recommendation, or favoring by the United States Government or the University of California. The views and opinions of authors expressed herein do not necessarily state or reflect those of the United States Government or the University of California, and shall not be used for advertising or product endorsement purposes. 


\section{DISCLAIMER}

Portions of this document may be illegible in electronic image products. Images are produced from the best available original document. 


\title{
Diode Laser Absorption Spectroscopy for Process Control- Sensor System Design Methodology* $\star$
}

\author{
L. V. Berzins ${ }^{+}$, T. M. Anklam, F. Chambers, S. Galanti, C. A. Haynam, E. F. Worden \\ Lawrence Livermore National Laboratory \\ P.O. Box 808 , L-470 \\ Livermore, CA 94550
}

\begin{abstract}
A laser absorption spectroscopy (LAS) system has been developed at Lawrence Livermore National Laboratory (LLNL) for process control. LAS has proven itself to be an accurate and reliable method to monitor both density and composition. In this paper the important features and components of an industrial LAS diagnostic are described. Application of this approach to vaporization processes requires careful selection of the species and transitions to be monitored. The relative vapor pressure, hyperfine structure, isotopic frequency shifts, and electronic temperature all effect the selection of a particular transition. In this paper we describe the methodology for choosing the optimal transition or transitions. Coevaporation of a titanium-niobium alloy is used to illustrate the methodology. In a related paper, T. M. Anklam et al describe the application of this diagnostic to monitoring and controlling composition in a physical vapor deposition process of industrial interest.
\end{abstract}

* Work performed under the auspices of the U.S. Department of Energy by the Lawrence Livermore National Laboratory under Contract W-7405-ENG-48.

$\star$ A portion of this work was supported by the ARPA Metal Matrix Composite Model Factory Program.

+ Author to whom correspondence should be addressed. 


\section{Introduction}

Titanium is a critical component in many high performance aircraft alloys. Aircraft engines in particular rely on titanium alloys for their high specific strength and stiffness at elevated temperatures. Next generation engine designs require even better high temperature performance[1]. Titanium matrix composites are one of the avenues being explored to meet these goals[2]. High materials costs in the production of titanium matrix composites requires both efficient and high rate coating of the silicon carbide fibers with the bulk material. Electron beam physical vapor deposition is a leading candidate for the production of titanium matrix composites.

Electron beam physical vapor deposition (EB-PVD) is a well established method for high rate vapor deposition. The major limitation with EB-PVD coatings is the preferential vaporization of the higher vapor pressure constituents. When the constituent vapor pressures are within a factor of approximately 100 , steady state vaporization with the proper vapor composition can be achieved. However, when the vapor pressures of the alloy constituents differ by significantly larger factors, the vapor composition tends to fluctuate. Active correction for these fluctuations is possible if the vapor composition is known.

Diode laser absorption spectroscopy is an ideal technique for measuring the absolute vapor composition and providing a feedback signal to a composition control system. In this paper we describe the methodology for selecting a titanium atomic transition for use in a diode laser absorption spectroscopy system. This methodology is applicable to the other constituents in titanium alloys as well as to other processes and alloys. 


\section{Past Results}

LLNL has been using laser absorption spectroscopy to monitor vapor densities for over 15 years. Laser absorption spectroscopy (LAS) has proven itself to be an accurate and reliable method to monitor both density and composition. During this time the diagnostic has moved from a research tool to being a robust component in a process control system.

In laser absorption spectroscopy laser light is swept in wavelength through the atomic transition of interest. The amount of light absorbed by the vapor is directly related to the vapor density. By sweeping the laser through the atomic transition and establishing the zero absorption baseline, absolute calibration is maintained for every scan. The narrow line width of the laser together with the large separation of atomic transitions compared to the transition line width insures no interference from other elements.

Figure 1 illustrates the components in an industrial diode-based LAS diagnostic. A diode laser tuned to the atomic transition of interest delivers light via fiber optics to the vacuum vessel. External to the vessel a portion of the light is focused on to a reference detector. The remainder of the light is launched through the vapor plume and measured by the signal detector. Chopping the light, together with synchronous detection, minimizes the effects of power fluctuations in the laser and external noise sources. The ratio of the signal to the reference yields the transmission as a function of frequency. The transmission is then

turned into a density by application of Beer's Law, $T=e^{-n \sigma^{l}}$ where $T$ is the transmission, $\mathrm{n}$ is the density, $\sigma$ is the atomic transition's cross section, and 1 is the path length of the laser light through the vapor. This density is then delivered to a model-based vaporizer control system. The control system uses the density to adjust the feed rates and electron beam power to maintain the desired vaporization rates. Multiple components can be monitored and controlled by tuning lasers to each component of interest. 


\section{Methodology}

The LAS sensor system must be designed to match the process of interest. For EB-PVD, relative vapor pressures, vaporization rate, electronic temperature, isotopic frequency shifts, and hyperfine structure all effect the selection of the appropriate atomic transition(s). Each of these issues needs to be addressed in order to select the appropriate element(s) and transition(s) to monitor. Below we examine each of these issues for the vaporization of titanium and niobium consistent with production of intermetallic titanium alloys such as $\mathrm{Ti}_{2} \mathrm{AlNb}$. The methodology of designing a vapor composition diagnostic and control system is shown schematically in Figure 2.

The first step in designing a vapor composition diagnostic is understanding the density range of interest and the associated vapor distribution and electronic temperature. At $2500 \mathrm{~K}$ the ratio of titanium to niobium vapor pressures is greater than $10,000[3]$. This large difference in vapor pressure will require monitoring both species in order to control vapor composition. Vaporization of titanium and niobium in approximately equal amounts is limited by the achievable niobium vaporization rate. Niobium is difficult to vaporize because of its high melting point and very low vapor pressure. Niobium vaporization rates of $1-2 \mathrm{~kg} / \mathrm{hr}$ are easily achievable.. At these niobium vaporization rates and for an atomic ratio of titanium to niobium of 2 , the corresponding titanium vaporization rates are also near $1-2 \mathrm{~kg} / \mathrm{hr}$. The vaporization rate is related to the vapor density via the vapor flux distribution. Efficient vaporization from a spot source is typically represented with a density distribution of the form

$$
n(r, \theta)=\frac{n_{100} r_{100}^{2}}{r^{2}} \cos ^{3} \theta,
$$


where $n(r, \theta)$ is the density at radius $r$ and angle $\theta$ from the vertical, and $n_{100}$ and $r_{100}$ are the density and radius at a point $100 \mathrm{~cm}$ directly above the source. For this calculation the flow velocity is assumed constant. The value of the flow velocity is calculated from a source temperature of $2500 \mathrm{~K}$ to be $1140 \mathrm{~m} / \mathrm{s}$ (neglecting internal degrees of freedom). Integration of the flux distribution over a half sphere yields the vaporization rate. For titanium vaporization rates near $2 \mathrm{~kg} / \mathrm{hr}, \mathrm{n}_{100}$ is $3.90 \times 10^{12}$ atoms $/ \mathrm{cm}^{3}$. With these relationships the vaporization rate can be related to the vapor density for any measurement geometry.

In order to calculate the density measured by the absorption diagnostic, both the fraction of titanium atoms in the state being monitored and the line integral of the vapor density along the laser path need to be calculated. At high vaporization rates, collisions bring the electronic energy states into equilibrium and relax the electronic temperature to between approximately $400 \mathrm{~K}$ and $1000 \mathrm{~K}$. For a Boltzmann distribution, the fraction of titanium atoms in each of the low lying metastable states is shown as a function of temperature in Figure 3. For comparison, Figure 4 shows the same plot for niobium. Clearly the titanium $170 \mathrm{~cm}^{-1}$ metastable level is the least sensitive to electronic temperature variations over the expected operating range. The titanium $170 \mathrm{~cm}^{-1}$ state density represents $34.8 \pm 0.5 \%$ of the total titanium density. This behavior makes the titanium $170 \mathrm{~cm}^{-1}$ state ideal for monitoring titanium vaporization. By contrast the variations of the niobium state densities with electronic temperature might require monitoring two niobium states in order to measure the absolute niobium density.

Calculation of the line integrated density requires knowledge of the measurement geometry. Our measurement geometry is shown in Figure 5. For a given shot location and vapor pathlength, the line-integrated density is 


$$
\begin{aligned}
\int n_{i} d l & =f_{i} n_{100} r_{100}^{2} \int \frac{\cos ^{3} \theta}{r^{2}} d l \\
& =\frac{2 f_{i} n_{100} r_{100}^{2}}{h}\left\{\frac{1}{3} \sin \theta\left(\cos ^{2} \theta+2\right)\right\}_{\theta=\tan ^{-1}\left(\frac{1}{2 h}\right)}
\end{aligned}
$$

where $n_{i}$ is the density in state $i, f_{i}$ is the fraction of the total density in state $i, h$ is the diagnostic laser standoff, $I$ is the vapor pathlength, and the rest of the symbols are defined above.

For the geometry shown in Figure 5 , the predicted line-averaged density, $\frac{\int \mathrm{nd} l}{1}$, in the titanium $170 \mathrm{~cm}^{-1}$ state is $6.4 \times 10^{12} \mathrm{~cm}^{-3}$. Using the line-averaged density, practical detection limits of $10 \%$ and $90 \%$ absorption, and Beer's Law, the acceptable titanium $170 \mathrm{~cm}^{-1}$ transition cross sections are from $3.2 \times 10^{-16} \mathrm{~cm}^{2}$ to $6.9 \times 10^{-15} \mathrm{~cm}^{2}$.

Before proceeding with a survey of potential transitions, the effects of isotopic shifts and hyperfine structure on the peak absorption need to be examined. For titanium the major isotope is ${ }_{22}^{48} \mathrm{Ti}$ with a natural abundance of $74 \%$. The rest of the titanium is split up among four isotopes. Therefore while the peak absorption in titanium may be somewhat smaller due to isotopic splitting, this is a minor effect for the purposes of selecting an atomic transition. In addition ${ }_{22}^{48} \mathrm{Ti}$ has no hyperfine structure to diminish the peak absorption. Niobium is in stark contrast to titanium. While there is only one naturally occurring isotope of niobium, its nuclear spin of $9 / 2$ insures a rich hyperfine structure. Figure 6 is an example of a niobium absorption trace which shows significant structure over a $30 \mathrm{GHz}$ region of frequency space. This structure causes several problems. First the peak intensity of the transition is significantly reduced. Therefore while the published 
cross section may appear large enough to monitor a given transition, the actual signal can be much smaller. In addition the large frequency extent of the transition puts more stringent requirements on the diode laser system.

Now that the process requirements have been examined, a survey of available titanium transitions is appropriate. There are 78 titanium transitions from ground and low lying metastable levels with wavelengths longer than $385 \mathrm{~nm}$. Of these transitions approximately $38 \%$ lack cross section information. For those transitions with cross section information [4], nine are appropriate for monitoring titanium. Table I shows the atomic transitions appropriate for monitoring titanium at vaporization rates of up to $2 \mathrm{~kg} / \mathrm{hr}$.

Having identified usable atomic transitions is not sufficient. The selected atomic transition must match available diode laser technology. Since the wavelengths of diode lasers are set by the band gap energy of the lasing material, diode lasers are available only in discrete wavelength regions. In addition for spectroscopic measurements the diode laser should operate $\mathrm{cw}$ in a single longitudinal mode and be scannable in frequency. Figure 7 shows the commercially available fundamental diode lasers as well as wavelengths where frequency doubled diodes are expected to be available soon. Frequency doubled diodes for spectroscopy applications require at least $100 \mathrm{~mW}$ of single longitudinal mode output at the fundamental wavelength in order to produce usable levels of blue to ultraviolet light. Waveguide doubler technology using periodically poled-lithium niobate[5,6] is being commercialized for these wavelengths. Table I shows the overlap between titanium transitions useful at high vaporization rates together with available diode technology. Clearly the titanium $170 \mathrm{~cm}^{-1}$ transitions at $391.588 \mathrm{~nm}$ and $388.139 \mathrm{~nm}$ offer the best match between available transitions and available technology. Unfortunately different lasers are required to reach these two transitions. Therefore before specifying the laser wavelength it is useful to experimentally verify the performance of these transitions. An 
experimental verification of these desirable weak transitions is required since the published cross sections are only good to $30 \%$ and different sources can differ by factors of two or more[7,8]. Table II shows examples for niobium.

Using ring-dye and Ti:Sapphire lasers we have prototyped several of the transitions shown in Table I. Figure 8 shows typical absorption waveforms taken during one of these runs. The peak heights determine the relative strength of each transition. By measuring the vapor flow velocity and the run integrated absorption, the projected total amount of titanium vaporized is calculated. Comparison of the projected amount to the amount collected postrun on the substrate above the laser shot permits calibration of the transition cross sections. Together this information provides a high confidence in selecting the $391.588 \mathrm{~nm}$ titanium $170 \mathrm{~cm}^{-1}$ transition for monitoring titanium vaporization at high vaporization rates. Upon this basis New Focus, Inc. is building us a waveguide doubled diode laser system for operation near $391 \mathrm{~nm}$.

Having selected the $391.524 \mathrm{~nm}$ titanium $170 \mathrm{~cm}^{-1}$ transition to monitor titanium vaporization, it is important to understand the process conditions under which this transition will provide useful data. In Figure 8, the $391.524 \mathrm{~nm}$ titanium $170 \mathrm{~cm}^{-1}$ transition was approximately $25 \%$ absorbed at a standoff of $44.8 \mathrm{~cm}$, a pathlength of $26.6 \mathrm{~cm}$, and a titanium vaporization rate near $2.5 \mathrm{~kg} / \mathrm{hr}$. If the transmission is $T_{\mathrm{o}}$ at density $\mathrm{n}_{\mathrm{O}}$ then the density $\mathrm{C}^{*} \mathrm{n}_{\mathrm{O}}$ can be evaluated from the measured transmission $\mathrm{T}$ (using Beer's Law) as

$$
C=\frac{\ln (T)}{\ln \left(T_{\text {known }}\right)}
$$


From this relation, the range of vaporization rates the $391.524 \mathrm{~nm}$ titanium $170 \mathrm{~cm}^{-1}$ transition can monitor at a standoff of $44.8 \mathrm{~cm}$ is $0.7 \mathrm{~kg} / \mathrm{hr}$ to $20 \mathrm{~kg} / \mathrm{hr}$. These vaporization rates correspond to $10 \%$ and $90 \%$ absorbed. Also of interest is the range of standoffs applicable to this transition. For this part of the calculation a titanium vaporization rate of $1 \mathrm{~kg} / \mathrm{hr}$ and a $1 / \mathrm{r}^{2}$ fall off in the peak density is used. At $1 \mathrm{~kg} / \mathrm{hr}$ the range of standoffs where this transition has usable absorption is $10 \mathrm{~cm}$ to $47 \mathrm{~cm}$. Therefore the $391.524 \mathrm{~nm}$ titanium $170 \mathrm{~cm}^{-1}$ transition is applicable over a wide range of operating points and measurement geometries.

The waveguide-doubled diode laser system being delivered by New Focus, Inc. has an approximate tuning range of $\pm 1 \mathrm{~nm}$ around $391.5 \mathrm{~nm}$. While designed specifically for monitoring titanium, this laser should be able to monitor a number of elements, depending on exact process conditions. A cursory survey shows that at least 13 elements have potentially useful transitions within the tuning range of the first prototype device. These elements include cobalt, iron, molybdenum, niobium, and vanadium. All are critical components in various high performance alloys.

Fundamentally there is no reason this technology can not be used to produce devices with wavelengths as long as $500 \mathrm{~nm}$. Development of this technology, together with commercially available fundamental diodes, provides nearly continuous wavelength coverage from $380 \mathrm{~nm}$ to above $1000 \mathrm{~nm}$.

\section{Summary}

In the past industrial applications of electron beam vaporization have been limited by an inability to control product composition. Diode laser absorption spectroscopy provides an accurate and reliable method to measure vapor composition. Together with a control 
system, diode laser absorption spectroscopy can be used to maintain alloy composition. Success of such a system depends on the appropriate choice of atomic transition(s). In this paper we have outlined a methodology for choosing the optimal transition(s). Currently we are adapting this approach to the manufacture of metal matrix composites, thermal barrier coatings, and photovoltaics. 


\section{References}

1. A.I. Taub, R.L. Fleischer, Science, 243, 1989, p. 616.

2. J. Doychak, JOM, 44, 1992, p. 46.

3. C.B. Alcock, V.P. Itkin, M.K. Horrigan, Can. Met. Quarterly, 23, 1984, p. 309.

4. G.A. Martin, J.R. Fuhr, W.L. Wiese, JPhys. Chem. Ref. Data, 17 Supplement No. 3, 1988, p. 85.

5. E.J. Lim, M.M. Fejer, R.L. Byer, W.J. Kozlovsky, Electron. Lett, 25, 1989, p. 731.

6. M.L. Bortz, S.J. Field, M.M. Fejer, D.W. Nam, R.G. Waarts, D.F. Welch, IEEE Trans. Quantum Elec., 30, 1994, p. 2953.

7. C.H. Corliss, W.R. Bozman, Experimental Transition Probabilities for Spectral Lines of Seventy Elements, NBS Monograph, 53, 1962.

8. D.W. Duquette, E.A. Den Hartog, J.E. Lawler, J. Quant. Spectrosc. Radiat. Transfer, 35, 1986, p. , p. 281. 


\begin{tabular}{|l|l|l|l|}
\hline State $\left(\mathrm{cm}^{-1}\right)$ & Wavelength $(\mathrm{nm})$ & $\begin{array}{l}\text { Cross Section[5] } \\
\left(\mathrm{x} 10^{-15} \mathrm{~cm}^{2}\right)\end{array}$ & $\begin{array}{l}\text { Matching Diode } \\
\text { Laser Technology }\end{array}$ \\
\hline 0 & 446.210 & 1.24 & No \\
\hline 170 & 544.661 & 0.774 & Maybe \\
\cline { 2 - 4 } & 542.624 & 1.37 & Maybe \\
\cline { 2 - 4 } & 521.970 & 6.81 & No \\
\cline { 2 - 4 } & 469.365 & 2.36 & No \\
\cline { 2 - 4 } & 456.264 & 2.57 & No \\
\cline { 2 - 4 } & 449.624 & 2.68 & No \\
\cline { 2 - 4 } & 391.588 & $\sim 1.0$ & Yes \\
\cline { 2 - 4 } & 388.139 & 6.05 & Yes \\
\hline
\end{tabular}

\section{Table I}

Titanium transitions appropriate for monitoring high rate vaporization (around $2 \mathrm{~kg} / \mathrm{hr}$ ). 


\begin{tabular}{|l|l|l|l|l|}
\hline Element & $\begin{array}{l}\text { State } \\
\left(\mathrm{cm}^{-1}\right)\end{array}$ & $\begin{array}{l}\text { Wavelength } \\
(\mathrm{nm})\end{array}$ & $\begin{array}{l}\text { Cross Section } \\
\left(\times 10^{-15} \mathrm{~cm}^{2}\right)\end{array}$ & Reference \\
\hline $\mathrm{Nb}$ & 0 & 454.280 & $13.0(65)$ & 7 \\
\cline { 4 - 5 } & \multirow{N}{Nb}{} & 454 & $34.0(79)$ & 8 \\
\hline
\end{tabular}

Table II

Comparison of niobium cross sections available in the literature. 


\section{Figure Captions}

Figure 1

Components in an industrial composition sensor based on diode laser absorption spectroscopy.

Figure 2

Methodology for designing a vapor composition control system based on laser absorption spectroscopy.

Figure 3

Fractional population in the titanium low lying metastables as a function of internal (electronic) temperature. Calculation of the total vapor density requires knowledge of the electronic temperature.

Figure 4

Fractional population in the niobium low lying metastables as a function of internal (electronic) temperature. Notice that for the expected internal (electronic) temperature the ground state is not the most populated state.

Figure 5

Vaporizer and diagnostic laser measurement geometry for titanium vaporization. The vapor pathlength is calculated as the projected length from a point source propagating through the aperture. 
Figure 6

Niobium absorption trace for the $442.06 \mathrm{~nm}$ niobium $392 \mathrm{~cm}^{-1}$ transition. This structure is the result of 12 spectrally separated hyperfine components.

Figure 7

Power levels and wavelengths of commercially available diode lasers. Frequency doubled diodes require at least $100 \mathrm{~mW}$ of fundamental power.

Figure 8

Simultaneous absorption traces for two of the titanium transitions under consideration. 


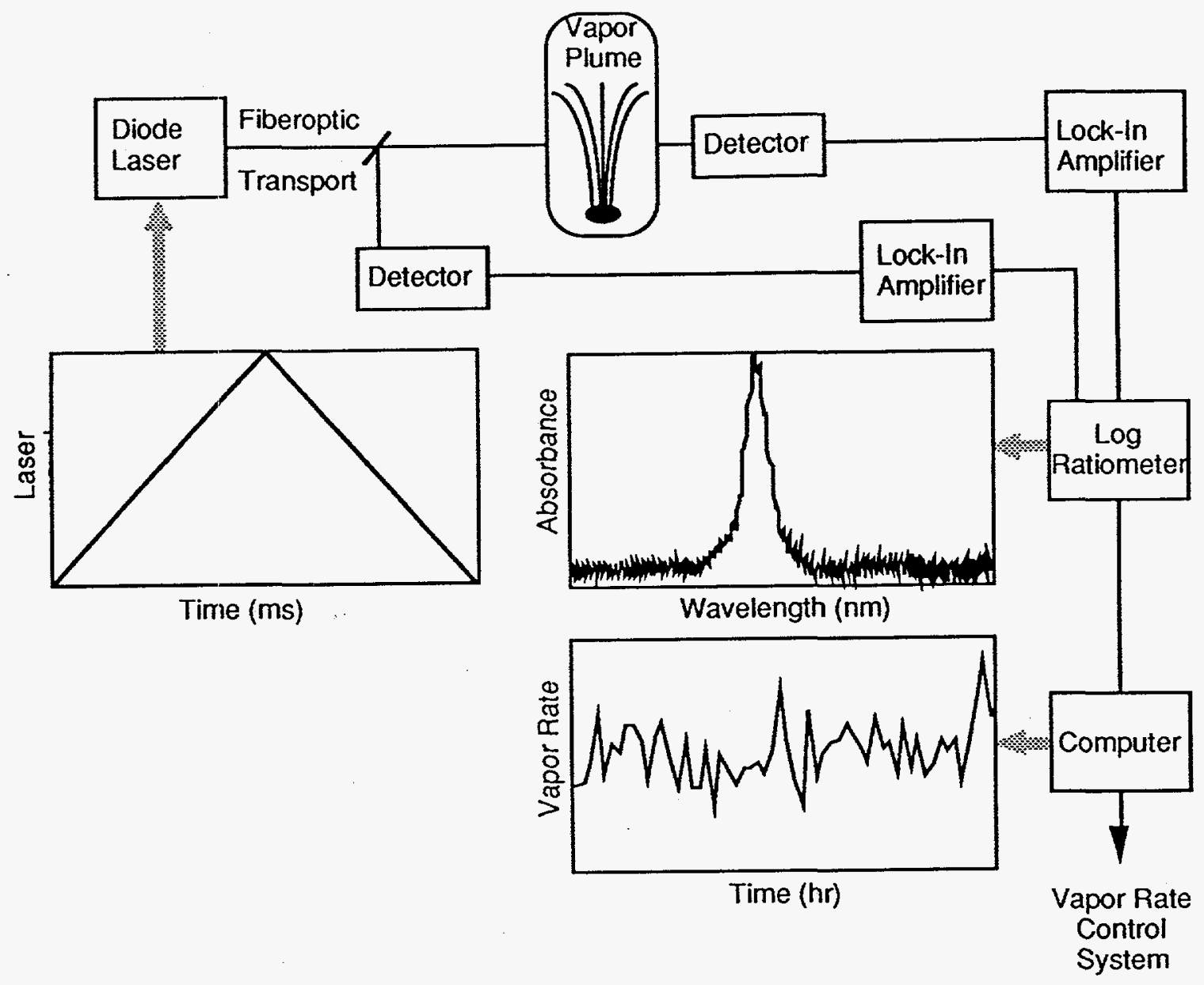

figure 1 


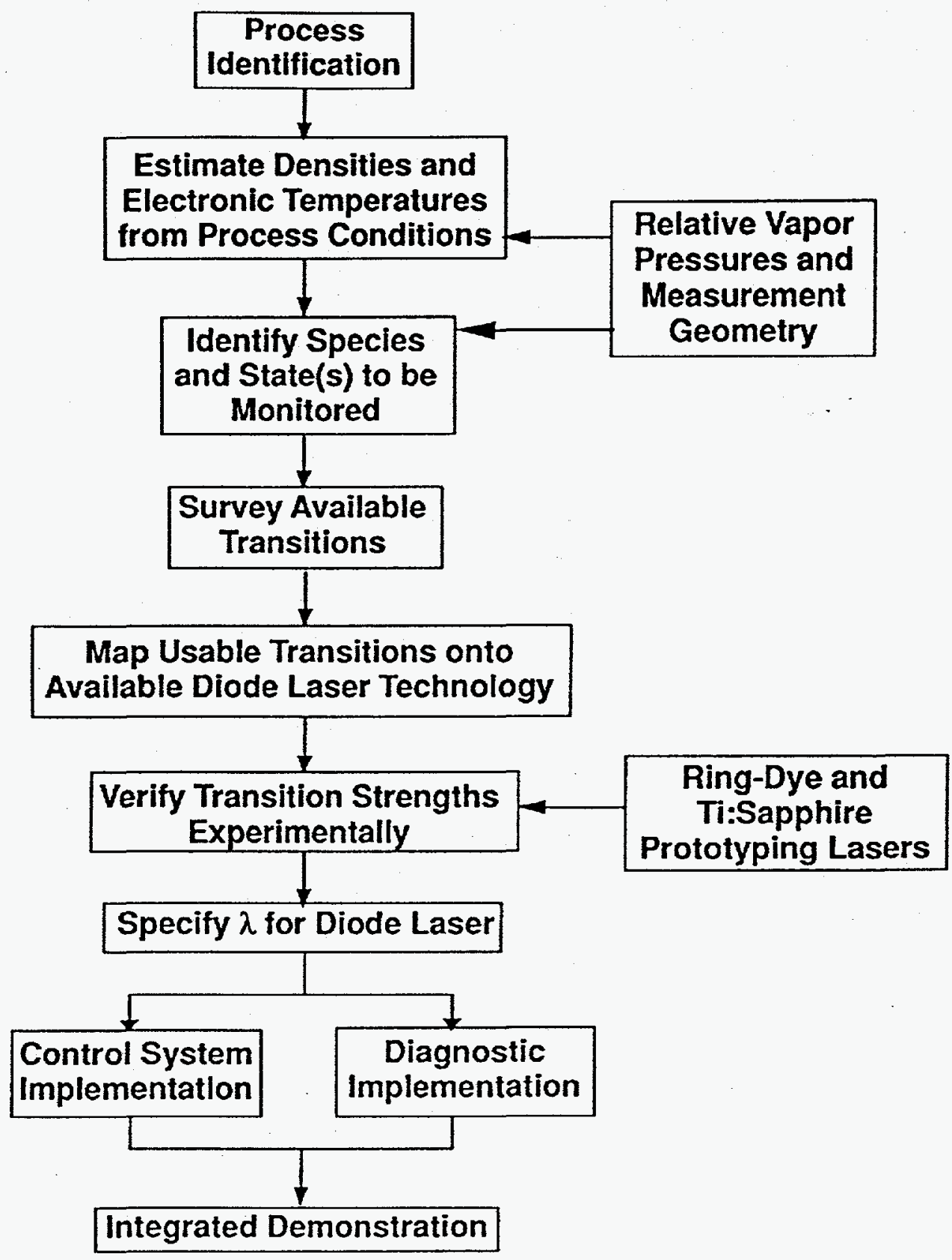

figure 2 


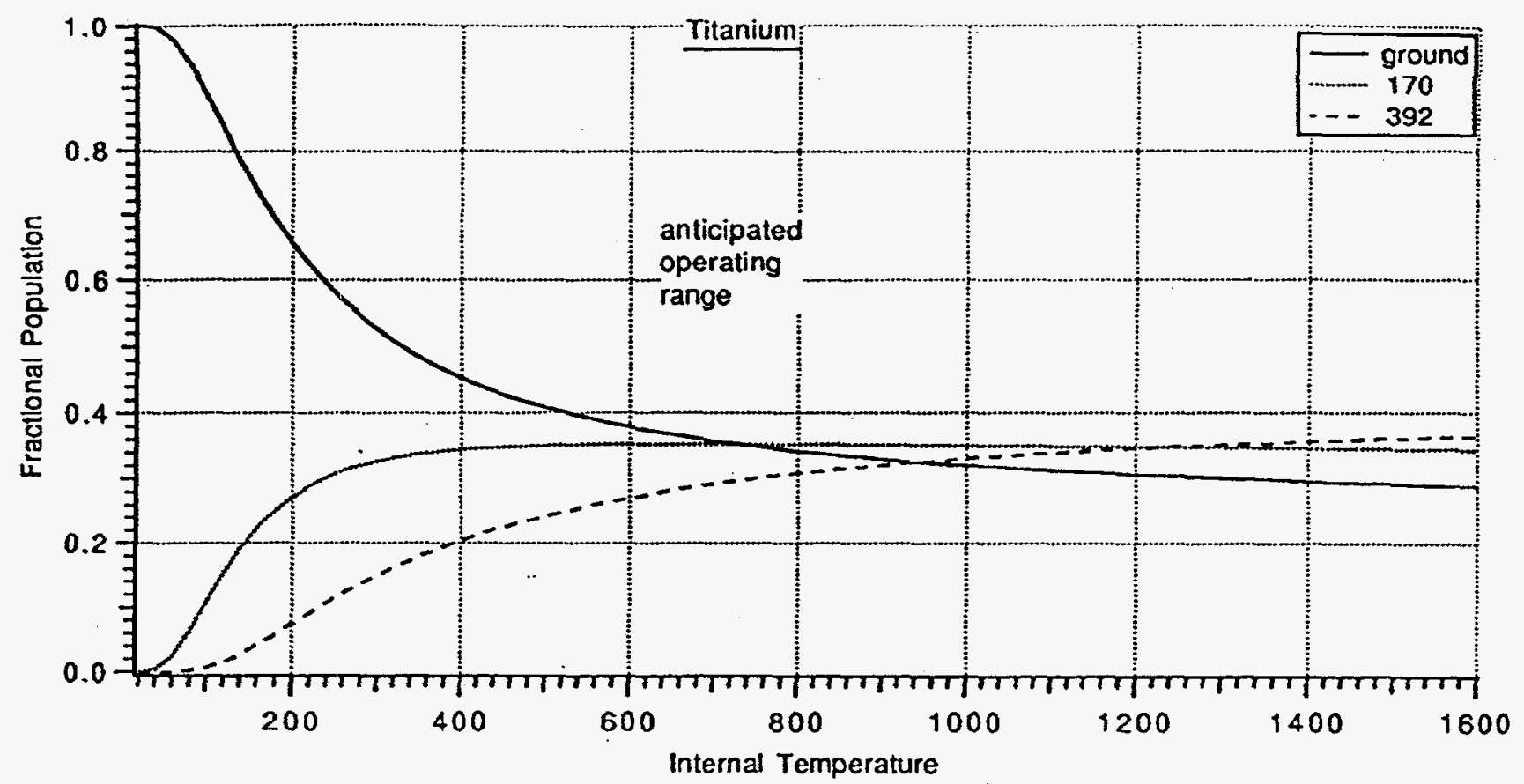

figure 3 


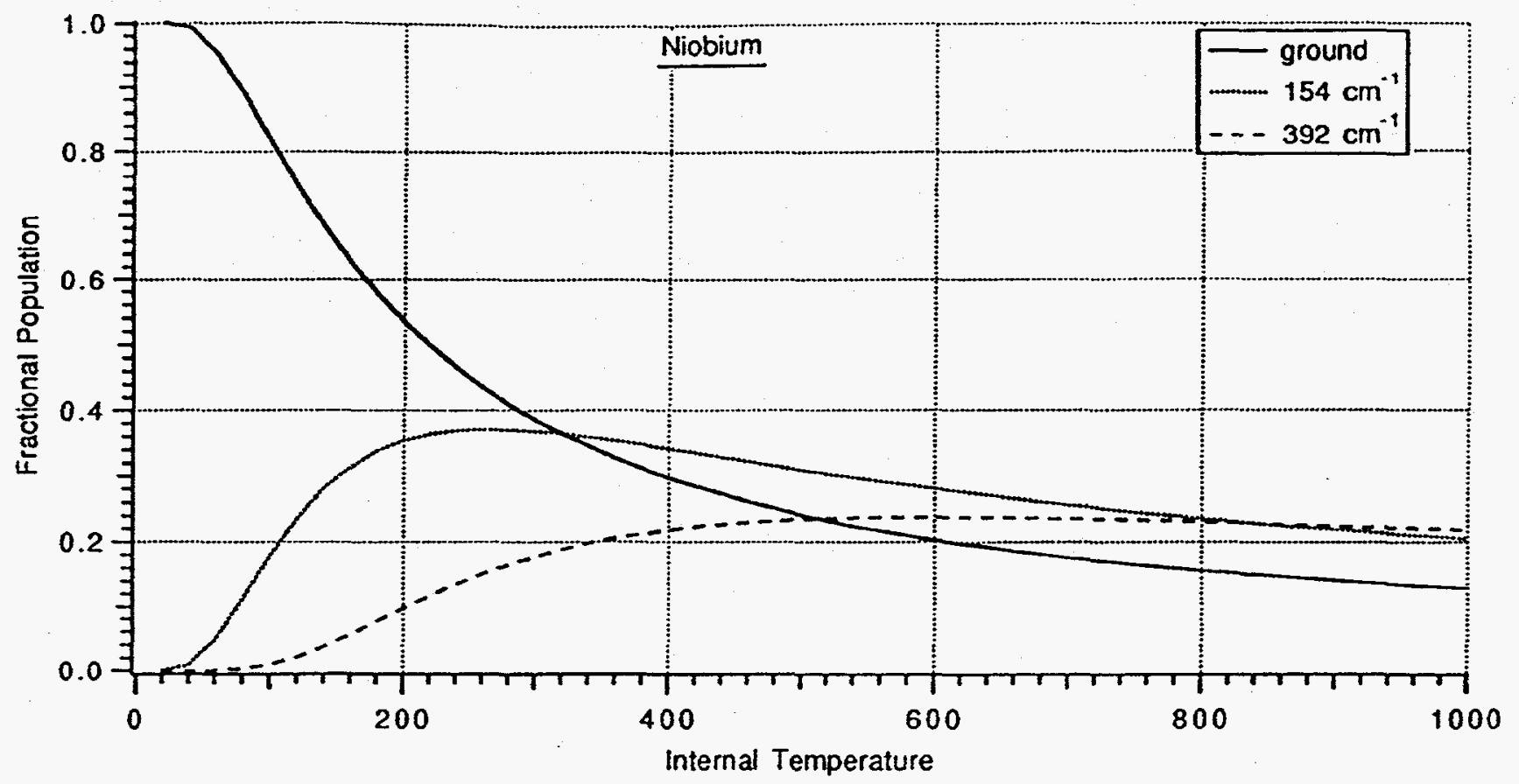

figure 4 
SIDE VIEW

(FACING NORTH)

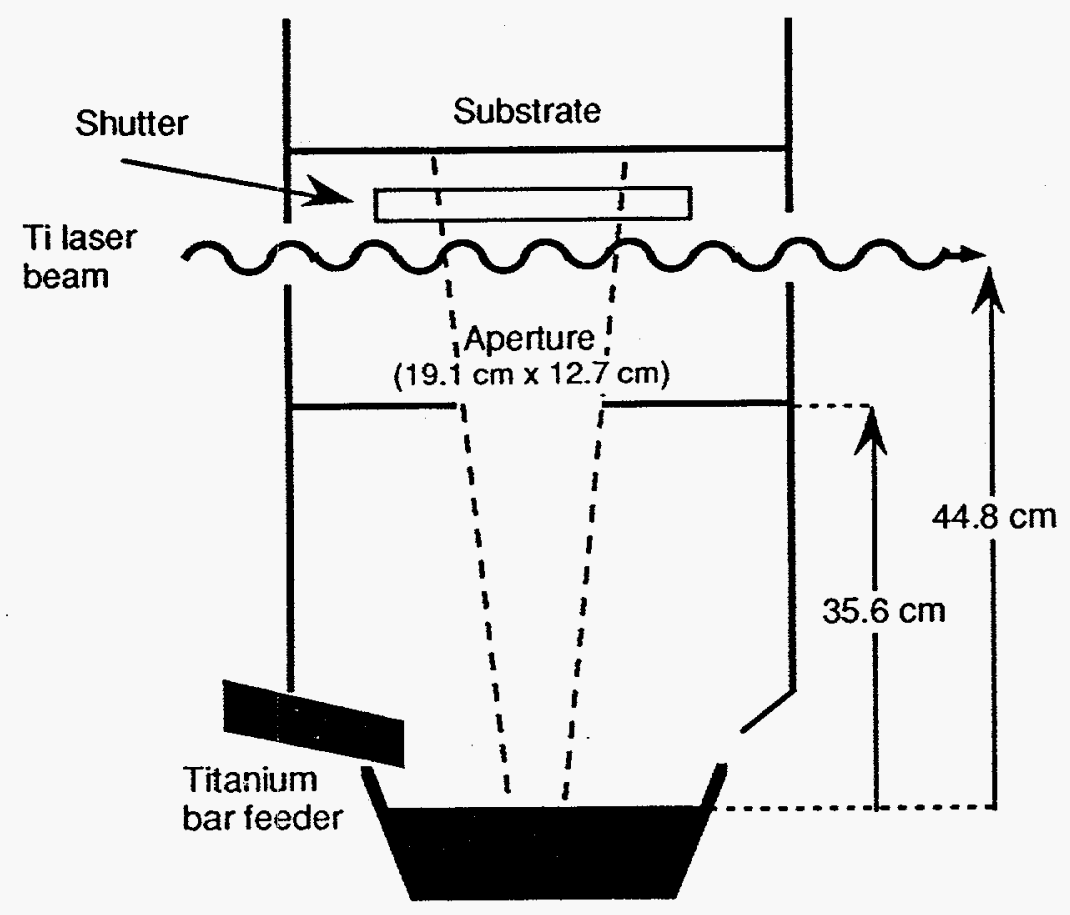

figure 5 


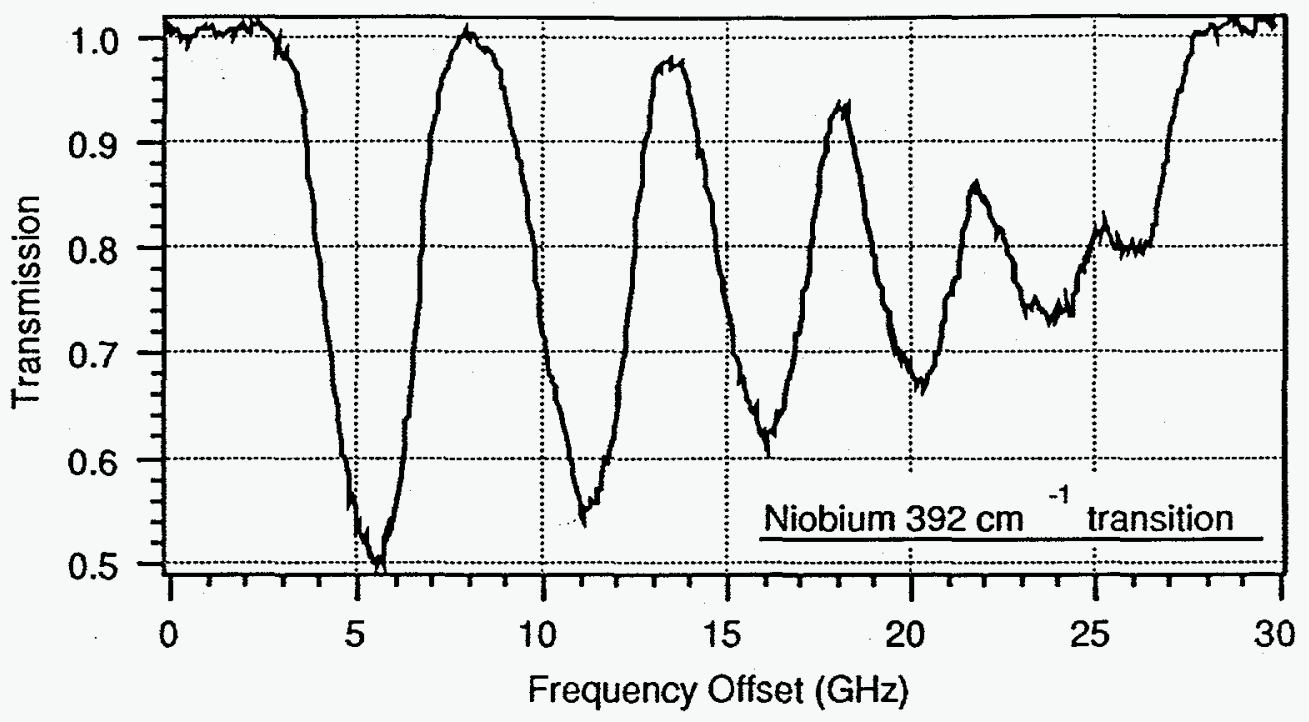

figure 6 
Available laser diodes

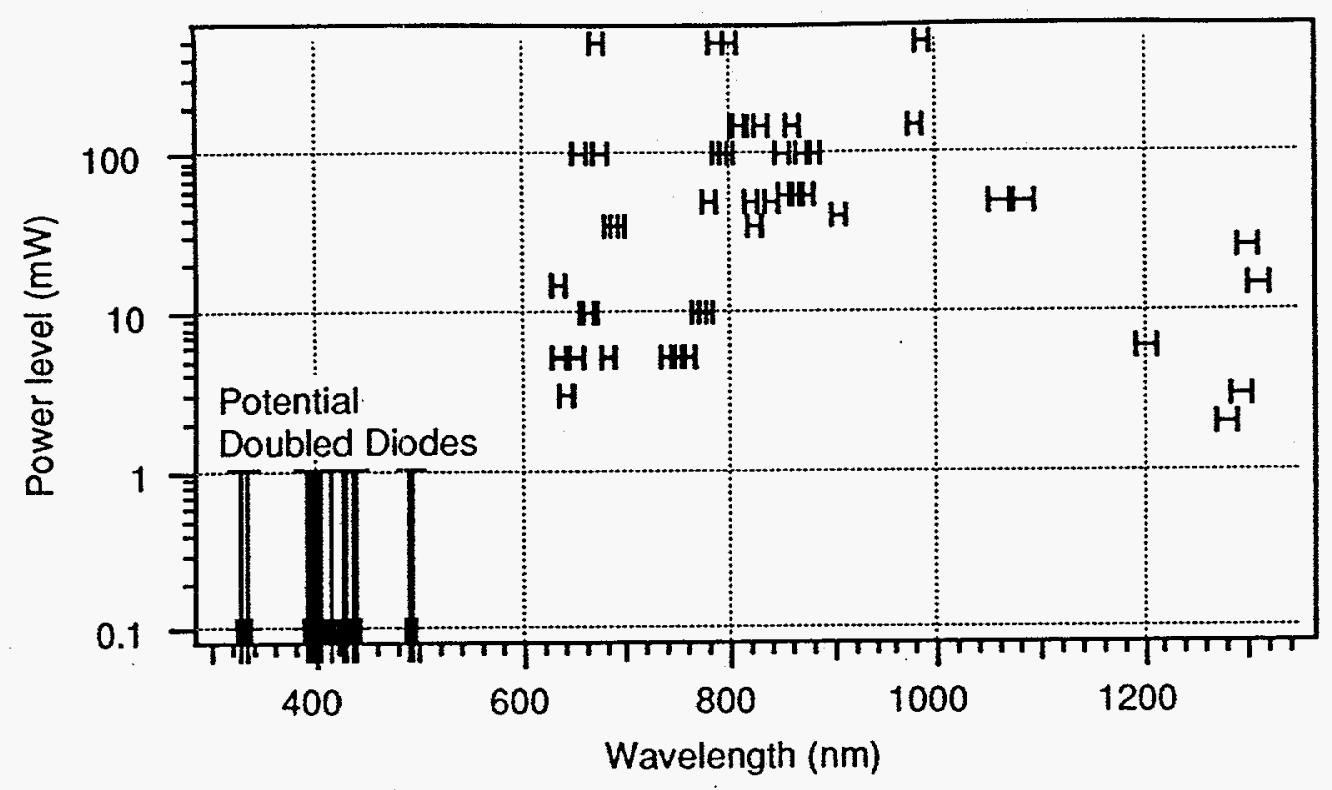

figure 7 


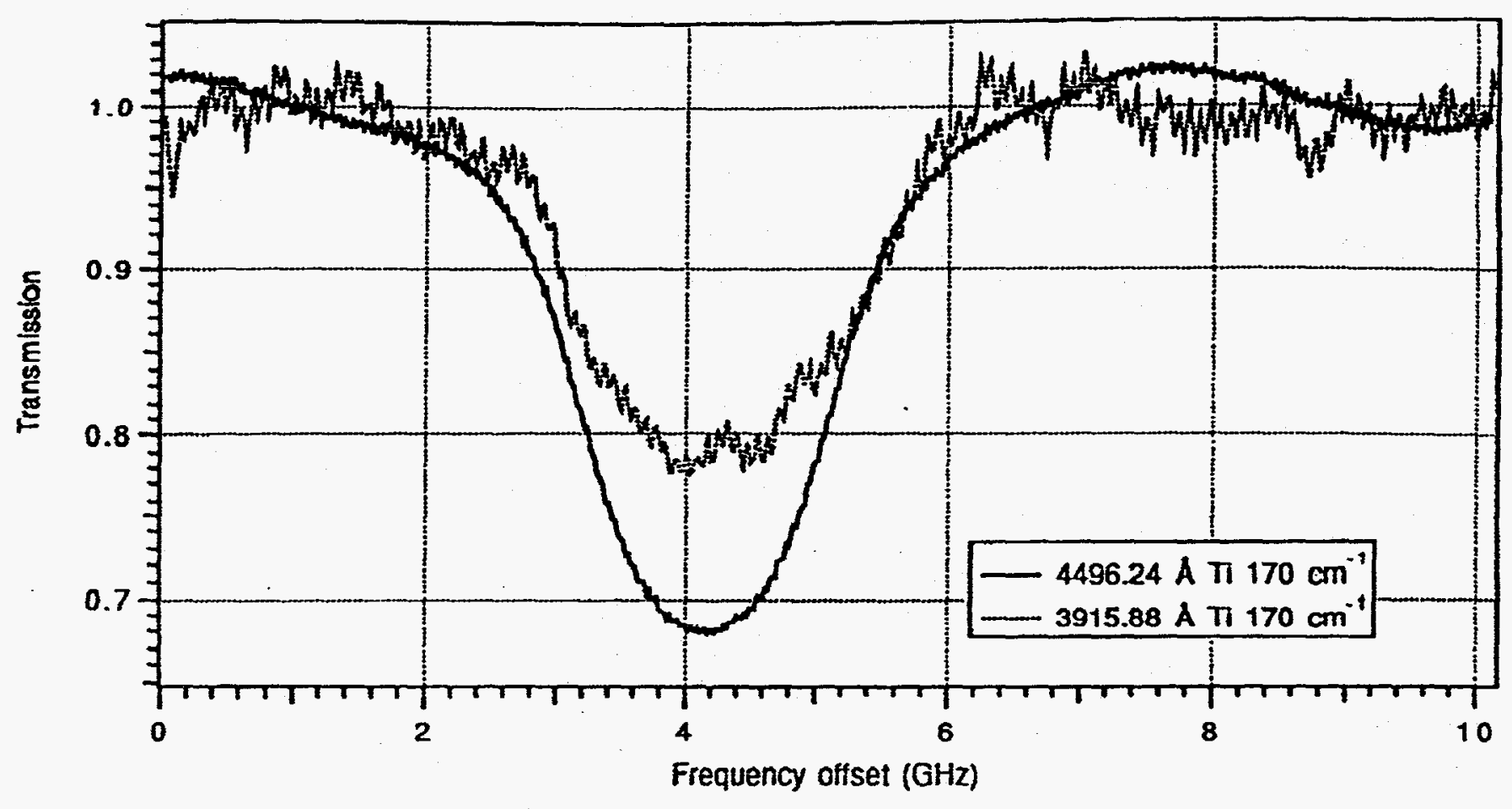

figure 8 